\title{
Multigram Scale Total Synthesis of Piperarborenines C-E
}

Jason L. Lenihan, ${ }^{\ddagger}$ Matthew J. Mailloux, ${ }^{\ddagger}$ and Aaron B. Beeler ${ }^{*}$

Department of Chemistry, Boston University, 590 Commonwealth Ave, Boston, Massachusetts 02215 (United States)

Abstract: We report the development of a multigram scale total synthesis of heterodimeric $\beta$ truxinic imides piperarborenines $C$-E using a catechol-mediated diastereoselective intramolecular [2+2] photocycloaddition. Key innovations lie in the use of (1) catechol as a highly selective auxiliary for the robust and scalable synthesis of homo- and heterodimeric $\beta$-truxinates, (2) UV LEDs for direct excitation in the [2+2] cycloaddition step, and (3) a bis pentafluorophenyl ester and LDA for the challenging installation of the syn dihydropyridinone imides. This approach is exceptionally scalable - requiring minimal chromatography, no photocatalysts, and no cryogenic conditions - and will enable thorough evaluation of the biological properties and anticancer profiles of piperaborenines $\mathrm{C}$ - $\mathrm{E}$ and derivatives thereof.

Piperarborenines A-E are cinnamic imide photo-dimers isolated from Piper arborescens, ${ }^{1}$ and are among the most active anticancer constituents known from the genus, with in vitro activities of C-E (1-3) ranging from 0.02-0.35 $\mu \mathrm{M}\left(\mathrm{IC}_{50}\right)$ against several cell lines. ${ }^{1,2}$ Piperlongumine (piplartine) - the [2+2] precursor of piplartine dimer $\mathrm{A}^{3}$ - and related derivatives have been the subject of extensive study in selective inhibition of cancer cells and suppression of tumor growth, ${ }^{4}$ re-sensitization of drug-resistant cancer strains, ${ }^{5}$ and other desirable effects. ${ }^{6}$ The collective body of literature has demonstrated piperlongumine as a strong candidate for cancer treatment, ${ }^{7}$ and the potential link between the activity of piperlongumine and its $\beta$-truxinic dimer point to the $\beta$ piperarborenines (1-3) as possible anticancer leads with improved potency. ${ }^{8}$ 

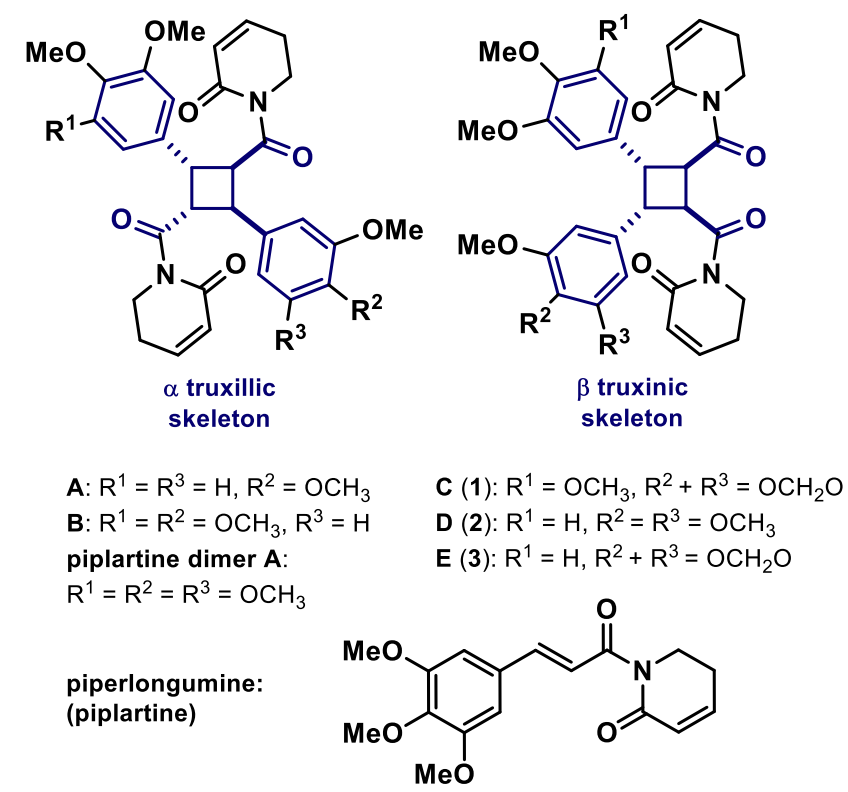

Figure 1. Piperarborenines $A-E$, piplartine $\operatorname{dimer} A$, and piperlongumine.

This work describes our development of a robust and highly scalable strategy for accessing these most potent $\beta$-truxinic congeners of the piperarborenine family. In addition to the piperarborenines, the dense structures and promising biological activities of other cyclobutane natural products have prompted considerable development in the construction of such scaffolds. ${ }^{9}$ In 2011, the $\mathrm{C}-\mathrm{H}$ functionalization driven total synthesis of piperarborenines B and D by Baran \& Gutekunst ${ }^{10}$ led to the structural reassignment of 1-3 as the $\beta$-truxinic ${ }^{11}$ imides, and in 2016 the groups of Tang \& $\mathrm{Xie}^{12}$ and Fox ${ }^{13}$ each reported total syntheses of piperarborenine B; these efforts led to notable innovations in asymmetric cyclobutane synthesis. Recently, a landmark work from $\mathrm{Hu} \& \mathrm{Su}$ reported a caged ruthenium(II) photocatalyst capable of highly-selective photodimerization of cinnamates and chalcones at low $\left(<1\right.$ mol\%) catalyst loadings. ${ }^{14}$ In the interest of scalability and utility in the synthesis of 1-3, we focused our efforts on developing a diastereoselective [2+2] photocycloaddition which required no photocatalysts, could be carried out in continuous flow, and relied minimally on chromatographic purifications.

In previous studies, our lab and others have demonstrated that intermolecular photodimerization of cinnamic esters strongly favors the $\delta$-diastereomer. ${ }^{15}$ Conversely, geometric confinement of cinnamates generally disfavors the $\delta$-diastereomer, thus favoring the $\beta$ diastereomer. ${ }^{16}$ Covalent, ${ }^{16 a-f}$ non-covalent, ${ }^{16 g-h}$ and solid-state ${ }^{17}$ strategies for selective [2+2] photocycloaddition of cinnamates and other alkenes have been covered in depth, ${ }^{18}$ and a wealth of auxiliaries or "templates" have been used to synthesize cyclobutanes with varied performance. In pursuit of a more practical method amenable to efficient synthesis of homo- and heterodimeric 
$\beta$-truxinate natural products, we sought an improved carboxylate linker which was (1) highly selective, (2) inexpensive, (3) operable in solution-phase, and (4) easily installed and removed in high yields. To this end, we screened commercially available alcohols and phenols in the following manner (Scheme 1): p-methoxycinnamic acid was coupled to the diol using EDC $\bullet \mathrm{HCl}$ and DMAP. The diester was then irradiated for 12 hours using a metal halide UV lamp, the percent conversion was determined by consumption of diester 4 , and the $\beta: \delta$ ratio $(5 \mathbf{a}: 5 \mathbf{b})$ was determined by ${ }^{1} \mathrm{H}$ NMR after hydrolysis with $\mathrm{LiOH} \bullet \mathrm{H}_{2} \mathrm{O}$ in $\mathrm{MeOH}$. Among a set of acyclic diols (Scheme 1a), threecarbon glycols 1,3-propanediol and neopentane glycol showed optimal conversion (88-95\%) and selectivity (>20:1 d.r.). ${ }^{19}$ Next, a small group of cyclic diols were tested, all of which showed poor to modest selectivity and/or conversion (Scheme 1b). Lastly, from a handful of phenols and benzylic alcohols, both catechol ${ }^{20}$ and phthalol ${ }^{21}$ provided high conversion and $\beta$-selectivity (Scheme 1c). Of the promising auxiliaries, catechol was chosen due to its low cost, high selectivity (>20:1 d.r.) and reaction rate, mild hydrolysis with carbonate bases, and good overall yield of $\mathbf{5 a}$ across three steps (>90\%).

Scheme 1. Evaluation of Diol Auxiliaries. ${ }^{\mathrm{a}}$

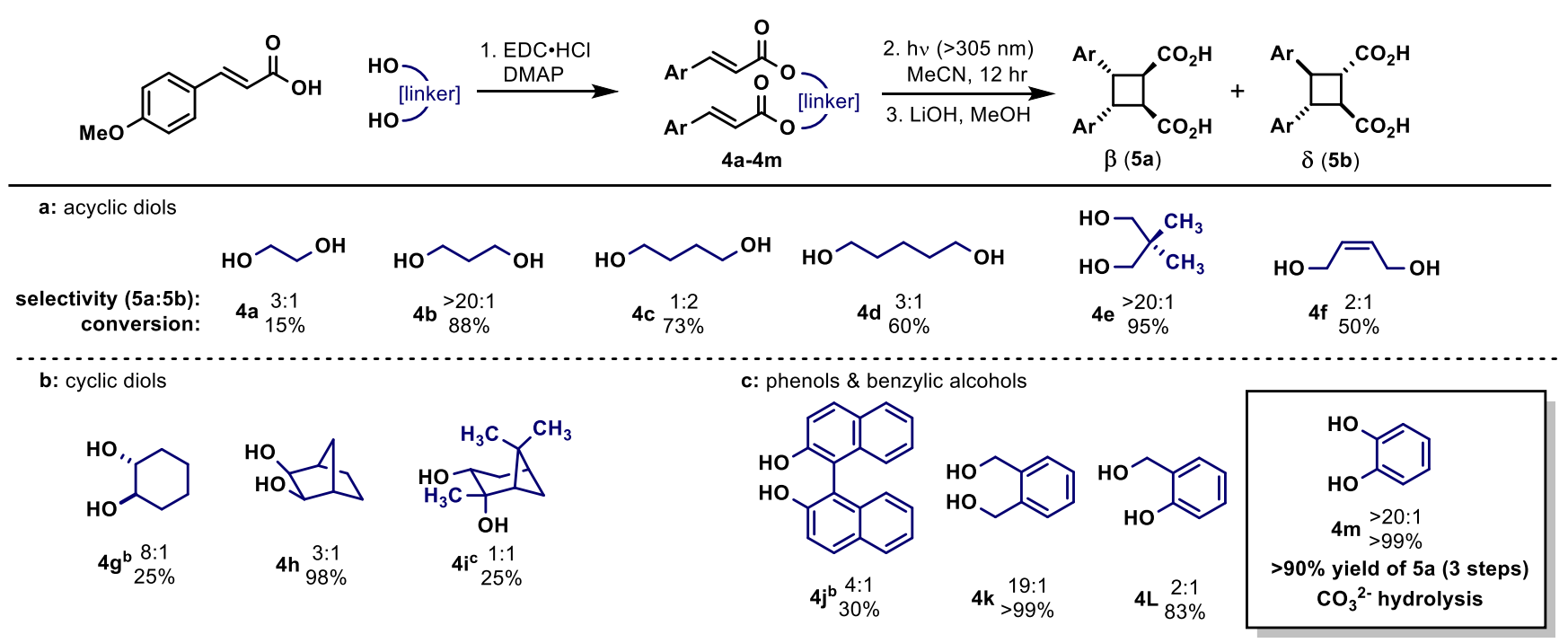

${ }^{a}$ Experimental details for auxiliary trials are in the Supporting Information. Compound numbers $(\mathbf{4 a}-\mathbf{4 m})$ denote the corresponding bis- $p$-methoxycinnamate esters for each auxiliary. $\mathrm{Ar}=p$-methoxyphenyl ${ }^{\mathrm{b}}$ racemic $^{\mathrm{c}}(+)-\alpha-$-pinanediol.

Given its prior synthesis and the availability of cinnamic acid precursors, we first assessed the utility of the catechol auxiliary in the synthesis of piperarborenine D (2) (Scheme 2). The forward synthesis began with two-step sequential esterification using 3,4-dimethoxy- and 3,4,5trimethoxycinnamic acids, and coupling reagent 2-(1H-benzotriazole-1-yl)-1,1,3,3tetramethylaminium tetrafluoroborate (TBTU). Formation of monoester 7 from 6 was promoted 
by use of excess (5 eq.) of catechol, which was readily removed in extractive workup. Use of close stoichiometric control of 3,4,5-trimethoxycinnamic acid and TBTU (1.00 eq. each) cleanly formed 8 in high yield (95\%, 2 steps), which was quickly stockpiled in decagram quantities. The UV-Vis spectrum of $\mathbf{8}$ showed a red-shifted $\lambda_{\max }$, greater extinction coefficient, and peak broadening compared to $\mathbf{4 m}$, which introduced the possibility of using UV LEDs in the photocycloaddition, rather than traditional metal halide lamps whose excessive heat can be difficult to manage. Based on this observation, we built a 140W $365 \mathrm{~nm}$ LED array which was used in a homemade large-capacity $(53 \mathrm{ml})$ flow photoreactor. Under optimized conditions in the [2+2] photocycloaddition ( $0.05 \mathrm{M}$ EtOAc, $15 \mathrm{~min}$ ), we achieved $6.4 \mathrm{~g}$ per hr rates of production of 9 in steady-state continuous flow, with projected productivity of $0.15 \mathrm{~kg}$ per day. From a small screen of conditions, we found that hydrolysis of $\mathbf{9}$ was efficiently carried out using $\mathrm{K}_{2} \mathrm{CO}_{3}$ under biphasic conditions (THF- $\mathrm{H}_{2} \mathrm{O}$ ). By this method, we obtained $3 \mathrm{~g}$ of $\beta$-truxinic acid $\mathbf{1 0}$ in a single pass, with >99\% mass recovery over two steps from 8 .

The final steps towards 2 involved installation of the dihydropyridinone imides. On review of the literature, we found the synthesis of mixed acyclic imides of the type in 1-3 to be somewhat sparse; the most common route is amide addition to an acyl chloride, ${ }^{22}$ although other methods have seen recent development. ${ }^{23}$ The most straightforward approach to 2 proved problematic, as attempts to form a bis acyl chloride from 10 resulted in formation of cyclic anhydride (12) using thionyl chloride, and oxalyl chloride with catalytic DMF ${ }^{24}$ Similarly, attempts to synthesize a bisHOBt (1-hyroxybenzotriazole) ester using TBTU and DIPEA resulted in anhydride (12) formation exclusively. The unique challenge of synthesizing activated esters on syn dicarboxylic acid 10 prompted further review of the mixed imide literature, where we found that $2,3,4,5,6$ pentafluorophenyl (PFP) esters react cleanly with $N$-metallated amides to provide mixed imides. ${ }^{25}$ Fortunately, synthesis of bis-PFP ester 11 proceeded without issue under standard conditions using $\mathrm{EDC} \cdot \mathrm{HCl}$. At this stage, a single chromatographic purification removed polar impurities which were carried through from the [2+2] and hydrolysis, giving $4 \mathrm{~g}$ of 11 (77\%). With 11 in hand, we tested conditions to achieve double imidation and complete the synthesis of 2 . Trials at 0-5 ${ }^{\circ} \mathrm{C}$ revealed that direct deprotonation of 5,6-dihydropyridin-2(1H)-one (DHP) with $n B$ Bui leads to uncontrolled reactivity. Alternatively, using lithium diisopropylamide (LDA) generated in situ as the base, double addition of Li-DHP to bis-PFP ester 11 was achieved in high yield (94\%), providing $2.8 \mathrm{~g}$ of piperarborenine $\mathrm{D}(2)$ in $68 \%$ overall yield in a single batch. 
Scheme 2. Synthesis of Piperarborenine D. ${ }^{a}$

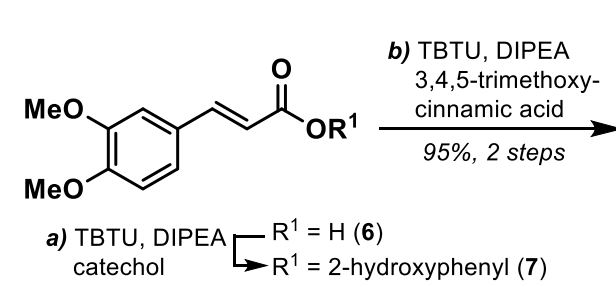

a) TBTU, DIPEA $\begin{aligned} & \mathrm{R}^{1}=\mathrm{H}(\mathbf{6}) \\ & \text { catechol }\end{aligned} \mathrm{R}^{1}=2$-hydroxyphenyl (7)

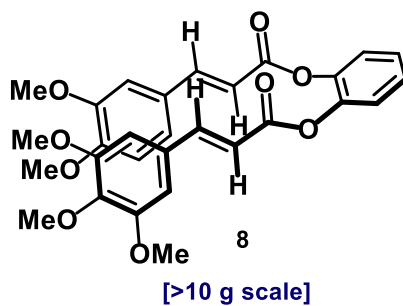

[>10 g scale] c) UV LEDs (>340 nm)

$15 \mathrm{~min}$, EtOAc

continuous flow

$6.4 \mathrm{~g} / \mathrm{hr}$

$0.15 \mathrm{~kg} /$ day*
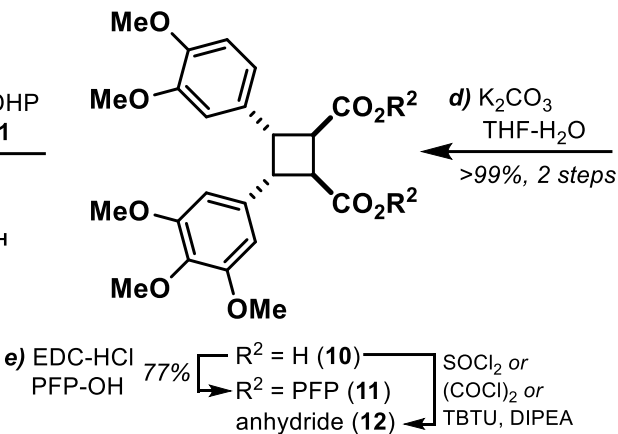
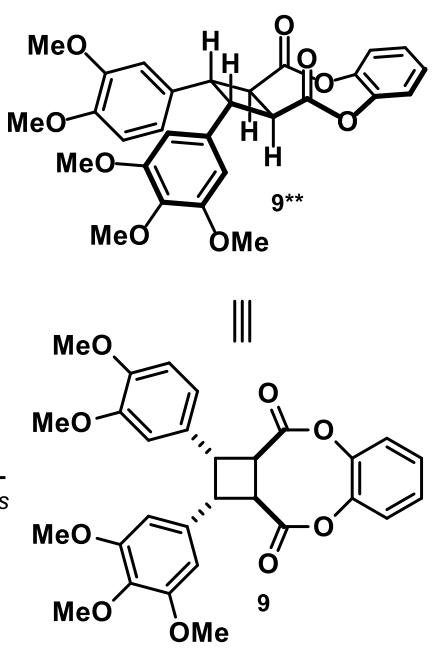

piperarborenine $D(2)$ $68 \%$ overall yield

[2.8 g prepared, single batch]

OMe

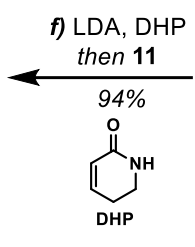

anhydride (12) 4 TBTU, DIPEA

a Reagents and conditions: (a) TBTU (1.0 eq.), DIPEA (5 eq.), 1:1 DCM:MeCN $(0.1 \mathrm{M}), 20{ }^{\circ} \mathrm{C}, 30$ min, then catechol $(5$ eq.), $15 \mathrm{~min}, 96 \%$; (b) 3,4,5-trimethoxycinnamic acid (1.00 eq.), DIPEA (5 eq.), TBTU (1.00 eq.), 1:1 DCM:MeCN (0.1 M), $20{ }^{\circ} \mathrm{C}, 30 \mathrm{~min}$ then 7, 3 hour, >99\%; (c-d) $365 \mathrm{~nm}$ LEDs, EtOAc (0.05 M), 20-25 ${ }^{\circ} \mathrm{C}, 15 \mathrm{~min}$ in flow, then; $\mathrm{K}_{2} \mathrm{CO}_{3}$ (10 eq.), $60{ }^{\circ} \mathrm{C}, 2 \mathrm{hr}$, THF: $\mathrm{H}_{2} \mathrm{O}(0.1 \mathrm{M} \mathrm{THF}),>99 \% 2$ steps (e) EDC·HCl (3 eq.), PFP-OH (3 eq.), DCM (0.1 M), $20{ }^{\circ} \mathrm{C}$, 3-6 hr, 77\%; (f) LDA (2.05 eq.), DHP (2.05 eq.), 0-5 ${ }^{\circ} \mathrm{C}$ (0.05 M THF), then 11, 94\%. * Projected rate ** Single enantiomer of 9 shown for clarity. Abbreviations: TBTU = 2- $(1 \mathrm{H}$-benzotriazole-1-yl)-1,1,3,3-tetramethylaminium tetrafluoroborate, $\mathrm{PFP}=$ 2,3,4,5,6-pentafluorophenyl, DHP = 5,6-dihydropyridin-2(1H)-one.

The synthesis of piperarborenines $\mathrm{C}$ and $\mathrm{E}$ ( $\mathbf{1}$ and $\mathbf{3}$ ) differed from $\mathbf{2}$ only in the preparation of the intermediate catechol monoester 14, which was made from myristicin-derived (7-methoxy1,3-benzodioxol-5-)yl cinnamic acid $\mathbf{1 3}$ using the prior TBTU coupling conditions in $88 \%$ yield (Scheme 3). While 13 is commercially available, its high cost and limited availability required its preparation in-house from myristicin aldehyde by Doebner-Knoevenagel condensation. Divergence in the second TBTU coupling using 3,4,5-trimethoxycinnamic acid and 3,4dimethoxycinnamic acid led to diesters 15 and 16, respectively, in high yields (95-99\%). While full conversion in the subsequent [2+2] photocycloaddition was achieved in 15 minutes at $0.05 \mathrm{M}$ for 15 and 8 , diester 16 required a $20 \mathrm{~min}$ residence time at $0.025 \mathrm{M}$ due to lower reactivity and solubility of the 3,4-dimethoxycinnamate. Under these conditions, 17 and 18 were produced in gram quantities in continuous flow at high $\mathrm{g}$ per $\mathrm{hr}$ rates. Hydrolysis and PFP esterification provided 21 and 22 with similar efficiency (68-71\%, 3 steps) to 11 . As with conversion of $\mathbf{1 1}$ to $\mathbf{2}$, a single chromatographic purification of $\mathbf{2 1}$ and $\mathbf{2 2}$ was sufficient to ensure high purity of the piperarborenine products. Double imidation of 21 and 22 using LDA and DHP provided 
piperarborenines $\mathrm{C}(\mathbf{1})$ and $E(\mathbf{3})$ in $93 \%$ and $91 \%$ yield, with overall yields of $55 \%$ and $54 \%$ from 13, respectively.

Scheme 3. Synthesis of Piperarborenines $C$ and $E .^{a}$
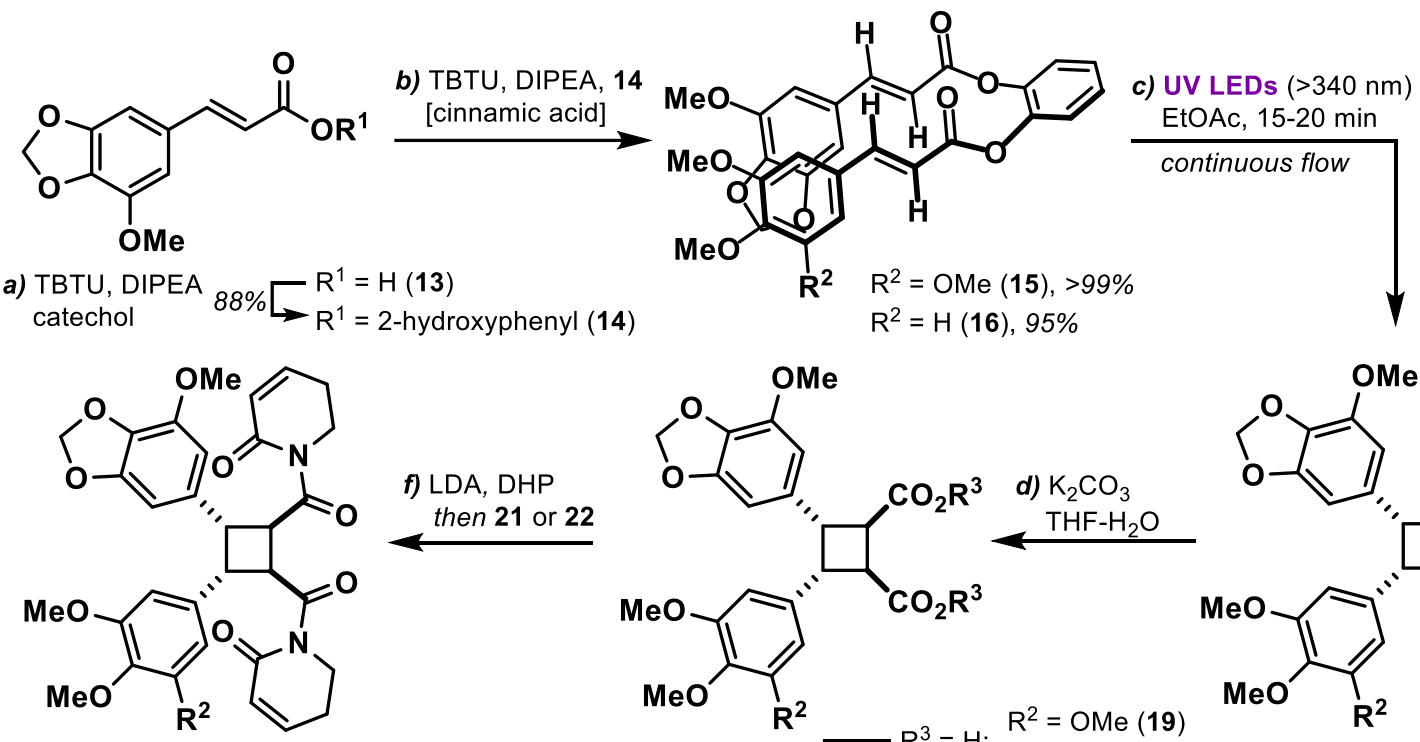

$\mathrm{R}^{2}=$ OMe (1), $93 \% ; 55 \%$ overall $[2.2 \mathrm{~g}]$

$\mathrm{R}^{2}=\mathrm{H}(3), 91 \% ; 54 \%$ overall $[1.8 \mathrm{~g}]$

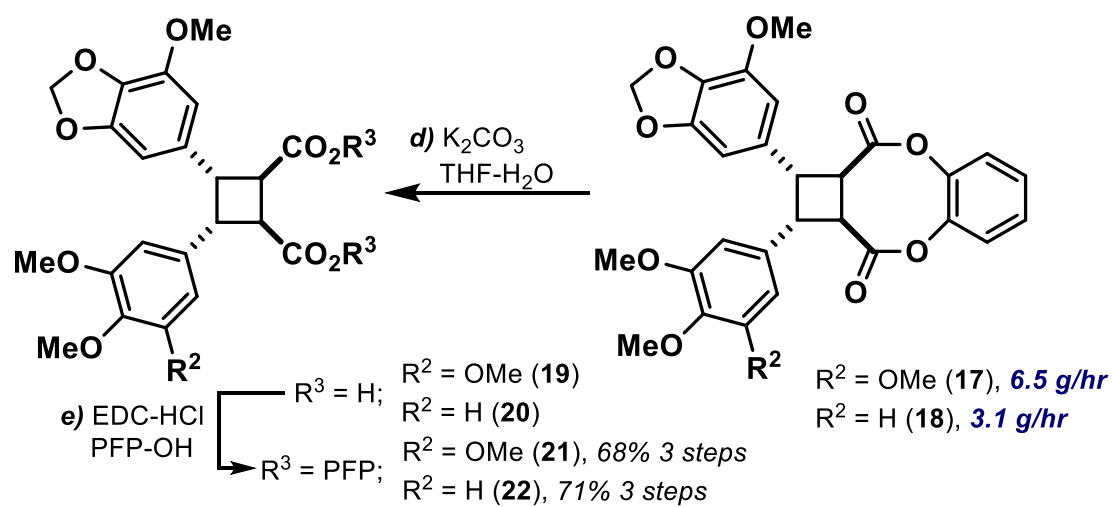

a Reagents and conditions: (a) TBTU (1.0 eq.), DIPEA (5 eq.), $30 \mathrm{~min}$, then catechol (5 eq.), 15 min, 1:1 DCM:MeCN (0.2 M), $20^{\circ} \mathrm{C}, 88 \%$; (b) TBTU (1.00 eq.), DIPEA (5 eq.), $30 \mathrm{~min}$, then [cinnamic acid] (1.00 eq.), 3 hour, 95-99\%; (c-d) $365 \mathrm{~nm}$ LEDs, EtOAc $(0.025-0.050 \mathrm{M}), 20-25^{\circ} \mathrm{C}, 15-20 \mathrm{~min}$ in flow, then; $\mathrm{K}_{2} \mathrm{CO}_{3}(10$ eq. $), 60{ }^{\circ} \mathrm{C}, \mathrm{THF}: \mathrm{H}_{2} \mathrm{O}, 2-3 \mathrm{hr}$, $>99 \% 2$ steps (19 and 20); (e) EDC $\cdot H C l$ (3 eq.), PFP-OH (3 eq.), DCM (0.1M), $20{ }^{\circ} \mathrm{C} 18$ hour, 78\% (21), 85\% ( 22); (f) LDA (2.05 eq.), DHP (2.05 eq.), $0-5^{\circ} \mathrm{C}$ (0.05 M THF), then 21 or 22, 93\% (1), 91\% (3).

In summary, we have developed a highly practical and diastereoselective intramolecular $[2+2]$ photocycloaddition for the synthesis of homo- and heterodimeric $\beta$-truxinates using catechol as an auxiliary. This approach was applied expediently to the 6-step total synthesis of anticancer leads piperarborenines $C, D$, and $E$ on multigram scale; access to such quantities will enable thorough evaluation of their biological activity. Should larger amounts of 1-3 or a related derivative be required, we imagine this route could be scaled quite readily. An investigation of the anticancer properties of 1-3 is underway in our group, and a thorough analysis of the scope, limitations, and applications of the catechol-mediated cyclobutane synthesis is forthcoming. 


\section{Author Information:}

Corresponding Author

* Aaron B. Beeler - Department of Chemistry, Boston University, Boston, Massachusetts 02215 (United States) ; email: beelera@bu.edu

\section{Authors}

Jason M. Lenihan - Department of Chemistry, Boston University, Boston, Massachusetts 02215 (United States)

Matthew J. Mailloux - Department of Chemistry, Boston University, Boston, Massachusetts 02215 (United States)

\section{Author Contributions}

$\ddagger$ J.L. and M.M. contributed equally.

\section{Acknowledgements}

The authors gratefully acknowledge Dr. Norman Lee of the Boston University Chemical Instrumentation Center for HRMS data, and the Jeffries-El Lab (Boston University) for assistance with validation of commercial LEDs.

\section{References}

(1) (a) Lee, F.-P.; Chen, Y.-C.; Chen, J.-J.; Tsai, I.-L.; Chen, I.-S. Cyclobutanoid Amides from Piper arborescens. Helv. Chem. Act. 2004, 87, 463-468. (b) Tsai, I.-L.; Lee, F.-P.; Wu, C.-C.; Duh, C.-Y.; Ishikawa, T.; Chen, J.-J.; Chen, Y.-C., Seki, H.; Chen, I.-S. New Cytotoxic Cyclobutanoid Amides, a New Furanoid Lignan and Anti-Platelet Aggregation Constituents from Piper arborescens. Planta Med. 2005, 71, 535-542.

(2) (a) Cunha, M. R.; Tavares, M. T.; Fernandes, T. B.; Parise-Filho, R. Peppers: A "Hot" Natural Source for Antitumor Compounds. Molecules 2021, 26, 1521-1542. (b) Parmar, V. S.; Jain, S. C.; Bisht, K. S.; Jain, R.; Taneja, P.; Jha, A.; Tyagi, O. D.; Prasad, A. K.; Wengel, J.; Olsen, C. E.; Boll, P. M. Phytochemistry of the Genus Piper. Phytochem. 1997, 46, 597-673.

(3) Filho, R. B.; De Souza, M. P.; Mattos, M. E O. Piplartine-Dimer A, a New Alkaloid from Piper Tuberculatum. Phytochem. 1981, 20, 345-346.

(4) (a) Adams, D. J.; Dai, M.; Pellegrino, G.; Wagner, B. K.; Stern, A. M.; Shamji, A. F.; Schreiber, S. L. Synthesis, Cellular Evaluation, and Mechanism of Action of Piperlongumine Analogs. Proc. Natl. Acad. Sci. 2012, 109, 15115-15120. (b) Boskovic, Z. V.; Hussain, M. M.; Adams, D. J.; Dai, M.; Schreiber, S. L. Synthesis of Piperlogs and Analysis of their Effects on Cells. Tetrahedron 2013, 69, 7559-7567. (c) Conde, J.; Pumroy, R. A.; Baker, C.; Rodrigues, T.; Guerreiro, A.; Sousa, B. B.; Marques, M. C.; de Almeida, B. P.; Lee, S.; Leites, E. P.; Picard, D.; Samanta, A.; Vaz, S. H.; Sieglitz, F.; Langini, M.; Remke, M.; Roque, R.; Weiss, T.; Weller, M.; Liu, Y.; Han, S.; Corzana, F.; Morais, V. A.; Faria, C. C.; Carvalho, T.; Filippakopoulos, P.; Snijder, B.; Barbosa- 
Morais, N. L.; Moiseenkova-Bell, V. Y.; Bernardes, G. J. L. Allosteric Antagonist Modulation of TRPV2 by Piperlongumine Impairs Glioblastoma Progression. ACS. Cent. Sci. 2021, 7, 868-881.

(5) (a) Zhang, C.; He, L.-J.; Zhu, Y.-B.; Fan, Q.-Z.; Miao, D.-D.; Zhang, S.-P.; Zhao, W.-Y.; Liu, X.-P. Piperlongumine Inhibits Akt Phosphorylation to Reverse Resistance to Cisplatin in Human Non-Small Cell Lung Cancer Cells via ROS Regulation. Front. Pharmacol. 2019, 10, 1178. (b) Machado, S.; Silva, A.; De Sousa-Coelho, A. L.; Duarte, I.; Grenho, I.; Santos, B.; Mayoral-Varo, V.; Megias, D.; Sanchez-Cabo, F.; Dopazo, A.; Ferreira, B.; Link, W. Harmine and Piperlongumine Revert TRIB2-Mediated Drug Resistance. Cancers 2020, 12, 3689. (c) Yao, Y.; Sun, Y.; Shi, M.; Xia, D.; Zhao, K.; Zeng, L.; Yao, R.; Zhang, Y.; Li, Z.; Niu, M.; Xu, K. Piperlongumine Induces Apoptosis and Reduces Bortezomib Resistance by Inhibiting STAT3 in Multiple Myeloma Cells. Oncotarget 2015, 7, 73497-73508.

(6) (a) Liang, J.; Ziegler, J. D.; Jahraus, B.; Orlik, C.; Blatnik, R.; Blank, N.; Niesler, B.; Wabnitz, G.; Ruppert, T.; Hübner, K.; Balta, E.; Samstag, Y. Piperlongumine Acts as an Immunosuppressant by Exerting Prooxidative Effects in Human T Cells Resulting in Diminished $\mathrm{T}_{\mathrm{H}} 17$ but Enhanced $\mathrm{T}_{\text {reg }}$ Differentiation. Front. Immunol. 2020, 11, 1172. (b) Thatikonda, S.; Pooladanda, V.; Sigalapalli, D. K.; Godugu, C. Piperlongumine Regulates Epigenetic Modulation and Alleviates Psoriasis-Like Skin Inflammation via Inhibition of Hyperproliferation and Inflammation. Cell Death and Disease 2020, 11, 21 . (c) de Lima Moreira, F.; Habenschus, M. D.; Barth, T.; Marques, L. M. M.; Pilon, A. C.; Bolzani, V. D.; Vessecchi, R.; Lopes, N. P.; de Oliveira, A. R. M. Metabolic Profile and Safety of Piperlongumine. Sci. Rep. 2016, 6, 33646.

(7) (a) Tripathi, S. K.; Biswal, B. K. Piperlongumine, a Potent Anticancer Phytotherapeutic: Perspectives on Contemporary Status and Future Possibilities as an Anticancer Agent. Pharm. Res. 2020, 156, 104772. (b) Bezerra, D. P.; Pessoa, C.; de Moraes, M. O.; Saker-Neto, N.; Silveira, E. R.; Costa-Lotufo, L. V. Overview of the Therapeutic Potential of Piplartine (Piperlongumine). Eur. J. Pharm. Sci. 2013, 48, 453-463. (c) Piska, K.; Gunia-Krzyźak, A.; Koczurkiewicz, P.; Wójcik-Pszczola, K.; Pękala, E. Piperlongumine (Piplartine) as a Lead Compound for Anticancer Agents - Synthesis and Properties of Analogues: A Mini-Review. Eur. J. Med. Chem. 2018, 156, 13-20.

(8) Sommerwerk, S.; Kluge, R.; Ströhl, D.; Heller, L.; Kramell, A. E.; Ogiolda, S.; Liebing, P.; Csuk, R. Synthesis, Characterization and Cytotoxicity of New Piplartine Dimers. Tetrahedron 2016, 72, 1447-1454.

(9) (a) Poplatana, S.; Tröster, A.; Zou, Y.-Q.; Bach, T. Recent Advances in the Synthesis of Cyclobutanes by Olefin [2+2] Photocycloaddition Reactions. Chem. Rev. 2016, 116, 9748-9815. (b) Wang, M.; Lu, P. Catalytic Approaches to Assemble Cyclobutane Motifs in Natural Product Synthesis. Org. Chem. Front. 2018, 5, 254-259. (c) Genzink, M. J.; Kidd, J. B.; Swords, W. B.; Yoon, T. P. Chiral Photocatalyst Structures in Asymmetric Photochemical Synthesis. Chem. Rev. 2021 (ahead of print). (d) Yoon, T. P. Photochemical Stereocontrol Using Tandem PhotoredoxChiral Lewis Acid Catalysis. Acc. Chem. Res. 2016, 49, 2307-2315. (e) Li, J.; Gao, K.; Bian, M.; Ding, H. Recent Advances in the Total Synthesis of Cyclobutane-Containing Natural Products. Org. Chem. Front. 2020, 7, 136-154.

(10) Baran, P. S.; Gutekunst, W. R. Total Synthesis and Structural Revision of the Piperarborenines via Sequential Cyclobutane C-H Arylation, J. Amer. Chem. Soc. 2011, 133, 19076-19079. 
(11) Resources and graphics for truxinate/truxillate diastereomer nomenclature (e.g. $\alpha, \beta)$ are provided in the Supporting Information.

(12) Hu, J.-L.; Feng, L.-W.; Wang, L.; Xie, Z.; Tang, Y.; Li, X. Enantioselective Construction of Cyclobutanes: A New and Concise Approach to the Total Synthesis of (+)-Piperarborenine B. J. Amer. Chem. Soc. 2016, 138, 13151-13154.

(13) Panish, R. A.; Chintala, S. R.; Fox, J. M. A Mixed-Ligand Chiral Rhodium(II) Catalyst Enables the Enantioselective Total Synthesis of Piperarborenine B. Angew. Chem. Int. Ed. 2016, 55, 4983-4987.

(14) Wang, J.-S.; Wu, K.; Yin, C.; Li, K.; Huang, Y.; Ruan, J.; Feng, X.; Hu, P.; Su, C.-Y. CageConfined Photocatalysis for Wide-Scope Unusually Selective [2+2] Cycloaddition Through Visible-Light Triplet Sensitization. Nat. Commun. 2020, 11, 4675-4684.

(15) (a) Telmesani, R.; Park, S. H.; Lynch-Colameta, T.; Beeler, A. B. [2+2] Photocycloaddition of Cinnamates in Flow and Development of a Thiourea Catalyst. Angew. Chem. Int. Ed. 2015, 54, 11521-11525. (b) Pagire, S. K.; Hossain, A.; Traub, L.; Kerres, S.; Reiser, O. Photosensitized Regioselective [2+2]-Cycloaddition of Cinnamates and Related Alkenes. Chem. Comm. 2017, 53, $12072-12075$.

(16) (a) Kuzuya, M.; Tanaka, M.; Hosoda, M.; Noguchi, A.; Okuda, T. Experimental and Theoretical Study on Methoxy Substituent Effect and Topotactic Assistance of Intramolecular Photocyclization of Polymethylene Dicinnamates. Nippon Kagaku Kaishi 1984, 1, 22-31. (b) Yagci, B. B.; Zorlu, Y.; Türkmen, Y. E. Template-Directed Photochemical Homodimerization and Heterodimerization Reactions of Cinnamic Acids. J. Org. Chem. 2021, 86, 13118-13128. (c) König, B.; Leue, S.; Horn, C.; Caudan, A.; Desvergne, J.-P.; Bouas-Laurent, H. Synthesis of Medium-Size Macrocycles by Cinnamate [2+2] Photoaddition. Liebigs Ann. 1996, 1231-1233. (d) Zitt, H.; Dix, I.; Hopf, H.; Jones, P. G. 4,15-Diamino[2.2]-paracyclophane, a Reusable Template for Topochemical Reaction Control in Solution. Eur. J. Org. Chem. 2002, 2298-2307. (e) Ghosn, M. W.; Wolf, C. Stereocontrolled Photodimerization with Congested 1,8-Bis(4'anilino)naphthalene Templates. J. Org. Chem. 2010, 75, 6653-6659. (f) Haag, D.; Scharf, H.-D. Investigations of the Asymmetric Intramolecular [2+2] Photocycloaddition and Its Application as a Simple Access to Novel $\mathrm{C}_{2}$-Symmetric Chelating Bisphosphanes Bearing a Cyclobutane Backbone. J. Org. Chem. 1996, 61, 6127-6135. (g) Sutyak, K. B.; Lee, W.; Zavalij, P. V.; Gutierrez, O.; Davis, J. T. Templating and Catalyzing [2+2] Photocycloaddition in Solution Using a Dynamic G-Quadruplex. Angew. Chem. Int. Ed. 2018, 57, 17146-17150. (h) Jiang, Y.; Wang, C.; Rogers, C. R.; Kodaimati, M. S.; Weiss, E. A. Regio- and Diastereoselective Intermolecular [2+2] Cycloadditions Photocatalysed by Quantum Dots. Nat. Chem. 2019, 11, 1034-1040. (i) Other selective [2+2] strategies are covered thoroughly in reviews (refs 9a, 17, 18).

(17) Biradha, K.; Santra, R. Crystal Engineering of Topochemical Solid State Reactions. Chem. Soc. Rev. 2013, 42, 950-967.

(18) (a) Svoboda, J.; König, B. Templated Photochemistry: Towards Catalysts Enhancing the Efficiency and Selectivity of Photoreactions in Homogeneous Solutions Chem. Rev. 2006, 106, 5413-5430. (b) Ramamurthy, V.; Sivaguru, J. Supramolecular Photochemistry as a Potential Synthetic Tool: Photocycloaddition Chem. Rev. 2016, 116, 9914-9993.

(19) This phenomenon was first identified in ref $16 \mathrm{a}$.

(20) An early report with both ethylene glycol (aryl termini) and catechol (carboxylate termini) linkers exhibited similar high $\beta$-selectivity: Akabori, S.; Tsuchiya, S. The Preparation of Crown 
Ethers Containing Dicinnamoyl Groups and Their Complexing Abilities. Bull. Chem. Soc. Jpn. 1990, 63, 1623-1628.

(21) Similar results with phthalol have been reported previously in ref $16 \mathrm{c}$.

(22) (a) Li, L.; Zhao, Y.; Cao, R.; Lin, L.; Cai, G.; Li, J.; Qi, X.; Chen, S.; Zhang, Z. Activity-Based Protein Profiling Reveals GSTO1 as the Covalent Target of Piperlongumine and a Promising Target for Combination Therapy for Cancer Chem. Commun. 2019, 55, 4407-4410. (b) Rao, V. R.; Muthenna, P.; Shankaraiah, G.; Akileshwari, C.; Babu, K. H.; Suresh, G.; Babu, K. S.; Kumar, R. S. C.; Prasad, K. R.; Yadav, P. A.; Petrash, J. M.; Reddy, G. B.; Rao, J. M. Synthesis and Biological Evaluation of New Piplartine Analogues as Potent Aldose Reductase Inhibitors (ARIs), Eur. J. Med. Chem. 2012, 57, 344-361. (c) Meegan, M. J.; Nathwani, S.; Twamley, B.; Zisterer, D. M.; O'Boyle, N. M. Piperlongumine (Piplartine) and Analogues: Antiproliferative MicrotubuleDestabilizing agents, Eur. J. Med. Chem. 2017, 125, 453-463. (d) Peng, S.; Zhang, B.; Meng, X.; Yao, J.; Fang, J. Synthesis of Piperlongumine Analogues and Discovery of Nuclear Factor Erythroid 2-Related Factor 2 (Nrf2) Activates as Potential Neuroprotective Agents, J. Med. Chem. 2015, 58, 5242-5255.

(23) (a) Brandhofer, T.; Gini, A.; Stockerl, S.; Pekarski, D. G.; Mancheño, O. G. Direct C-H Bond Imidation with Benzoyl Peroxide as a Mild Oxidant and a Reagent, J. Org. Chem. 2019, 84, 1299213002. (b) Kataoka, K.; Wachi, K.; Jin, X.; Suzuki, K.; Sasano, Y.; Iwabuchi, Y.; Hasegawa, J.; Mizuno, N.; Yamaguchi, K. CuCl/TMEDA/nor-AZADO-Catalyzed Aerobic Oxidative Ccylation of Amides with Alcohols to Produce Imides, Chem. Sci. 2018, 9, 4756-4768. (c) Other methods are discussed and referenced in refs 23a and 23b.

(24) Anhydride formation from the truxinic acid using oxalyl chloride was first reported in Baran's synthesis (ref 10).

(25) (a) Andrus, M. B.; Li, W.; Keyes, R. F. Synthesis of Microcolin B, a Potent New Immunosuppressant Using and Efficient Mixed Imide Formation Reaction. J. Org. Chem. 1997, 62, 5542-5549. (b) Andrus, M. B.; Li, W.; Keyes, R. F. Synthesis of Mixed Ccyclic Imides using Penafluorophenyl Esters. Tetrahedron Lett. 1998, 39, 5465-5468.

\section{Table of Contents Graphic:}

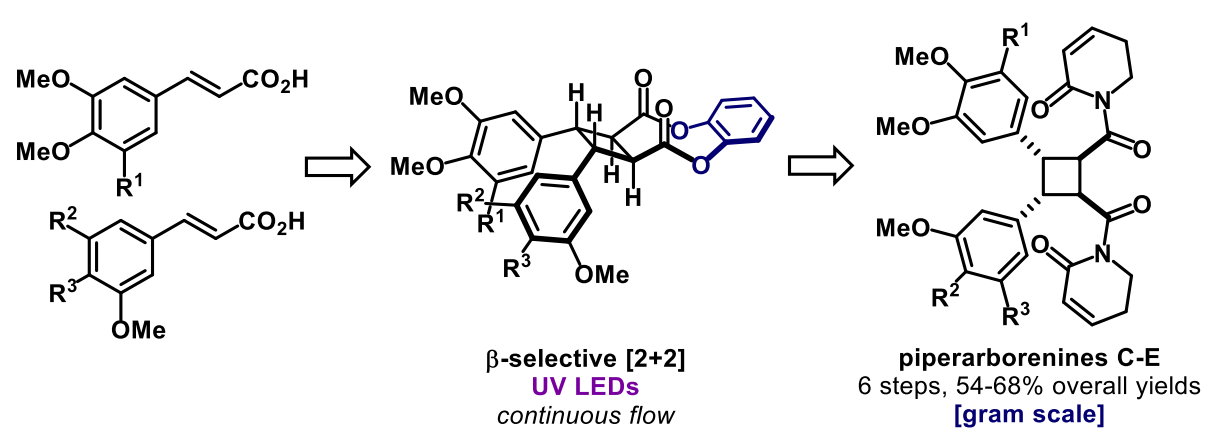

